\title{
IndiCAdoRES BIológICOS de EXPosiçÃo (IBE) a Agentes QuímICOS
}

\author{
J. P. SOUSA ${ }^{1, *}$, M. L. Pereira ${ }^{2}$
}

\begin{abstract}
A cos costos a diversas substâncias quimicas constitui uma preocupação constante no âmbito da saúde ocupacional. Este trabalho salienta a importância dos indicadores biológicos de exposição na monitorização contínua de indivíduos expostos a esses agentes em ambiente profissional, com destaque para os laboratórios químicos. Na União Europeia, muitos são os países que assumem como valores de referência para os valores limite de exposição (VLE) e índices biológicos de exposição (IBE) a agentes químicos os recomendados pela American Conference of Governamental Industrial Hygienist (ACGIH). Ao nível nacional, também os VLE constantes da NP 1796, datados de 2007, têm por base a ACGIH. Na legislação portuguesa (Decreto-Lei n.․․ 247/89), em termos de IBE, só existem valores para a exposição ao chumbo, em que é fixado em termos de ácido-aminolevulínico em urina de $20 \mathrm{mg} / \mathrm{g}$ de creatinina.
\end{abstract}

\section{INTRODUÇÃO}

Entende-se por indicador biológico um parâmetro apropriado avaliado num meio biológico do trabalhador, medido num determinado momento e, estando associado, direta ou indiretamente, com a exposição global, isto é, por todas as vias de entrada no organismo de um determinado agente químico. Como meios biológicos utilizam-se o ar exalado, a urina, o sangue, saliva, suor e outros, de acordo com o documento produzido pelo Instituto Nacional de Seguridade e Higiene en el Trabajo (INSHT) em 2011 [1]. Neste artigo, define-se um parâmetro, no meio de medição e no momento de recolha da amostra. Esta medida pode indicar a intensidade de uma exposição recente, a exposição média diária ou a quantidade total do agente acumulado no organismo, ou seja, o teor total do agente químico ou biológico.

O desenvolvimento de métodos e técnicas analíticas como os da biologia celular e molecular tem demonstrado a importância dos meios biológicos acima referidos como instrumentos valiosos na avaliação da exposição ocupacional e ambiental da população [2].

De acordo com o documento publicado pelo INSHT, consideram-se dois

\footnotetext{
Academia Militar, CINAMIL, MDN, Rua Gomes Freire, 1150-244 Lisboa

Departamento de Biologia, CICECO, Universidade de Aveiro, 3810-193 Aveiro

* joaopsousa1@iol.pt
}

tipos de indicadores biológicos de exposição: i) IB de dose, o qual é um parâmetro que mede a concentração de um agente químico ou de algum dos seus metabolitos no meio biológico do trabalhador exposto; ii) IB de efeito, como sendo um parâmetro que pode identificar alterações bioquímicas reversíveis, induzidas de um modo característico pelo agente químico ao qual está exposto o trabalhador.

Prista e Uva (2006) referem a importância dos indicadores biológicos de exposição nos programas de prevenção da exposição profissional a agentes químicos, salientando as potencialidades e limitações no que concerne a doenças profissionais e/ou acidentes de trabalho [3].

Segundo Rosa (2004), para um agente químico com eficiência biológica, proceder-se-á à sua biomonitorização da avaliação da exposição total a produtos químicos presentes em locais de trabalho através da medida de um "determinante" apropriado em material biológico obtido de um trabaIhador num tempo específico [4]. Segundo o autor, os Índices Biológicos de Exposição (IBE) são valores que representam limites de determinantes (quantidade de substâncias ou seus metabolitos ou reação fisiológica) aos quais um trabalhador pode estar exposto sem risco demonstrável para a saúde e bem estar.

A utilização dos IBE, no contexto de uma adequada implementação de estratégias de avaliação do risco de exposição a agentes químicos, é reconhecida internacionalmente como uma medida importante no âmbito da prevenção das doenças profissionais. O documento espanhol relativo aos valores limite de exposição (VLE) [1], adota como IBE, à semelhança de outros Estados-membros da União Europeia, os valores limite de exposição e os indicadores biológicos de exposição propostos pela ACGIH, publicado em 2009 [5]. O documento do INSHT é a ferramenta mais recente no que diz respeito a valores limite de exposição, quer a agentes químicos, quer a agentes biológicos.

Segundo consta dos documentos da ACGIH e do INSHT, entende-se por Indicador Biológico de Exposição a concentração de um marcador biológico resultante da exposição a um dado agente químico, em fluído biológico identificado e que corresponde ao resultado da monitorização de trabalhadores saudáveis expostos por inalação a concentrações ao nível do valor limite de exposição - média ponderada (VLE-MP) para aquele agente.

\section{VALORES DOS IBE}

A notação IBE é indicada quando é recomendado um índice biológico de exposição para um agente. A monitorização biológica deve ser instituída de forma a avaliar todas as fontes de exposição a determinado agente, incluindo a via cutânea, ingestão e exposição não profissionais. 
Na Tabela 1 encontram-se valores de IBE para alguns agentes químicos com predominância nos locais de trabalho e nos laboratórios de química. Apresenta-se uma comparação entre os IBE vigentes em Espanha (através do documento publicado pelo INSHT) e os estipulados pela ACGIH.

Refira-se que a nível nacional, a CERTITECNA coordena uma Comissão Técnica (CT-42), responsável pela atualização da NP-1796 com base nos valores estipulados no documento da ACGIH. A grande maioria dos Estados-membros da União Europeia também adota a política de transpor para os respetivos quadros norma- tivos os valores estipulados por este organismo americano.

Da Tabela 1 podemos constatar que os valores são, na sua esmagadora maioria, idênticos.

A monitorização biológica constitui uma ferramenta para a avaliação da exposição dos trabalhadores e do risco que tal exposição apresenta para a saúde do Homem. Uma correta monitorização dos agentes químicos nos locais de trabalho fomenta assim uma cultura preventiva, essencialmente ao nível das doenças profissionais. O indicador biológico de exposição pode ser: i) a própria substância quí- mica; ii) um ou mais metabolitos; iii) uma alteração bioquímica reversível característica, induzida pela substância química, de acordo com o estipulado pela $\mathrm{ACGIH}$.

\section{ReLAÇÃo entRe os IBE E VLE}

Os indicadores biológicos são biomarcadores de absorção individual de uma substância. A monitorização pessoal para determinar a exposição profissional indica a potencial exposição por inalação e via cutânea de um grupo de trabalhadores ou de um indivíduo. A grande maioria dos IBE é baseada numa correlação direta com o VLE [6]. Alguns dos IBE (ex. o

Tabela 1 - Valores de IBE vinculados pelo INSHT e pela ACGIH

\begin{tabular}{|c|c|c|}
\hline Nome do agente & IBE / INSHT & IBE / ACGIH \\
\hline Acetona & $50 \mathrm{mg} / \mathrm{L}$ & $50 \mathrm{mg} / \mathrm{L}$ \\
\hline Anilina & $50 \mathrm{mg} / \mathrm{g}$ creatinina & $50 \mathrm{mg} / \mathrm{L}$ \\
\hline Arsénio & $35 \mu \mathrm{g} \mathrm{As} / \mathrm{L}$ & $35 \mu \mathrm{g} \mathrm{As} / \mathrm{L}$ \\
\hline Cádmio e compostos inorgânicos & $5 \mu \mathrm{g} / \mathrm{g}$ creatinina & $5 \mu \mathrm{g} / \mathrm{g}$ creatinina \\
\hline Cádmio (no sangue) & $5 \mu \mathrm{g} / \mathrm{L}$ & $5 \mu \mathrm{g} / \mathrm{L}$ \\
\hline Ciclohexanona & $80 \mathrm{mg} / \mathrm{L}$ & $80 \mathrm{mg} / \mathrm{L}$ \\
\hline Cobalto (na urina) & $15 \mu \mathrm{g} / \mathrm{L}$ & $15 \mu \mathrm{g} / \mathrm{L}$ \\
\hline Cobalto (no sangue) & $1 \mu \mathrm{g} / \mathrm{L}$ & $1 \mu \mathrm{g} / \mathrm{L}$ \\
\hline Crómio (total na urina) & $10 \mu \mathrm{g} / \mathrm{L} ; 25 \mu \mathrm{g} / \mathrm{L}$ & $25 \mu \mathrm{g} / \mathrm{L} ; 10 \mu \mathrm{g} / \mathrm{L}$ \\
\hline Diclorometano & $0,3 \mathrm{mg} / \mathrm{L}$ & $0,3 \mathrm{mg} / \mathrm{L}$ \\
\hline $\mathrm{N}, \mathrm{N}$-Dimetilacetamida & 30mg/g creatinina & 30mg/g (creatinina) \\
\hline $\mathrm{N}, \mathrm{N}$-Dimetilformamida & $15 \mathrm{mg} / \mathrm{L}$ & $15 \mathrm{mg} / \mathrm{L}$ \\
\hline $\begin{array}{l}\text { Estireno (Ácido mandalélico mais ácido } \\
\text { fenilglioxílico na urina) }\end{array}$ & $\begin{array}{c}\text { 400mg/g creatinina } \\
(0,2 \mathrm{mg} / \mathrm{L} \text { em sangue venoso) }\end{array}$ & $\begin{array}{c}\text { 400mg/g creatinina } \\
(0,2 \mathrm{mg} / \mathrm{L} \text { em sangue venoso })\end{array}$ \\
\hline Etilbenzeno & 700mg/g creatinina & $0,7 \mathrm{~g} / \mathrm{g}$ de creatinina \\
\hline Fenol & $250 \mathrm{mg} / \mathrm{g}$ de creatinina & $250 \mathrm{mg} / \mathrm{g}$ de creatinina \\
\hline Fluoretos & $8 \mathrm{mg} / \mathrm{L}$ & $10 \mathrm{mg} / \mathrm{g}$ de creatinina \\
\hline 2-Furaldeido (Ácido furóico na urina) & $200 \mathrm{mg} / \mathrm{L}$ & $200 \mathrm{mg} / \mathrm{L}$ \\
\hline$n$-Hexano (2,5-Hexanodiona na urina) & $0,4 \mathrm{mg} / \mathrm{L}$ & $0,4 \mathrm{mg} / \mathrm{L}$ \\
\hline Mercúrio inorgânico total na urina e no sangue & $\begin{array}{c}35 \mu \mathrm{g} / \mathrm{g} \text { creatinina } \\
15 \mu \mathrm{g} / \mathrm{L}\end{array}$ & $\begin{array}{c}35 \mu \mathrm{g} / \mathrm{g} \text { creatinina } \\
15 \mu \mathrm{g} / \mathrm{L}\end{array}$ \\
\hline Metanol & $15 \mathrm{mg} / \mathrm{L}$ & $15 \mathrm{mg} / \mathrm{L}$ \\
\hline $\begin{array}{l}\text { Metil- } n \text {-butilcetona (2,5-Hexanodiaona na } \\
\text { urina) }\end{array}$ & $0,4 \mathrm{mg} / \mathrm{L}$ & $0,4 \mathrm{mg} / \mathrm{L}$ \\
\hline Metiletilcetona & $2 \mathrm{mg} / \mathrm{L}$ & $2 \mathrm{mg} / \mathrm{L}$ \\
\hline Metilisobutilcetona & $3,5 \mathrm{mg} / \mathrm{L}$ & $2 \mathrm{mg} / \mathrm{L}$ \\
\hline $\begin{array}{l}\text { Monóxido de carbono (Carboxilemoglobina no } \\
\text { sangue) }\end{array}$ & $3,5 \%$ carboxihemoglobina & $3,5 \%$ hemoglobina \\
\hline $\begin{array}{l}\text { Monóxido de carbono na fração final de ar } \\
\text { exalado }\end{array}$ & 20 ppm & 20 ppm \\
\hline Nitrobenzeno (p-Nitrofenol total em urina) & $5 \mathrm{mg} / \mathrm{g}$ creatinina & $5 \mathrm{mg} / \mathrm{g}$ creatinina \\
\hline Nitrobenzeno (Metahemoglobina no sangue) & $1,5 \%$ de hemoglobina & $1,5 \%$ de hemoglobina \\
\hline Paratião ( $p$-Nitrofenol total na urina) & $0,5 \mathrm{mg} / \mathrm{g}$ creatinina & $0,5 \mathrm{mg} / \mathrm{g}$ creatinina \\
\hline
\end{tabular}


chumbo) são resultado do VLE, mas relacionam-se diretamente como desenvolvimento de um efeito adverso na saúde.

Os IBE são apresentados como indicação da substância por meio da sua designação e dos respetivos números CAS (Chemical Abstract Service Registry Number). Os IBE são expressos em determinadas unidades, com base no tipo de amostra considerada. Assim, por exemplo, numa amostra de sangue, os IBE baseiam-se na percentagem de hemoglobina, enquanto que numa amostra de ar exalado, os IBE são expressos em ppm de ar exalado.

Os IBE são linhas de orientação para utilização na avaliação de riscos potenciais para a saúde na prática da higiene ocupacional e podem estar relacionados com o desenvolvimento de doenças profissionais, em caso de exposição prolongada dos trabalhadores. Os IBE não são indicadores de uma clara separação entre exposições perigosas e não perigosas. A título exemplificativo, é possível que a concentração de um indicador biológico de um dado indivíduo ultrapasse o correspondente IBE sem que isso represente um risco de saúde acrescido.

Se as medições das amostras recoIhidas num trabalhador em diferentes ocasiões excedem o valor do IBE de forma continuada, então a causa da ocorrência desse valor deve ser in- vestigada e devem ser tomadas ações para reduzir a exposição do trabalhador. Também deve ser realizada uma investigação quando a maioria das medições em amostras obtidas de um grupo de trabalhadores do mesmo turno e a desempenhar tarefas similares e no mesmo espaço, exceda os IBE.

Pode ser apropriada a retirada de um trabalhador de um local com exposição no seguimento de um resultado elevado da monitorização biológica, se houver razões que indiciem a ocorrência de uma exposição significativa. Ao contrário, resultados abaixo do valor IBE não significam necessariamente exposição ao risco associado. A nível nacional, o Decreto-Lei $n .^{\circ}$ 247/89, de 21 de Agosto, que tem por objetivo a proteção dos trabalhadores contra os riscos que possam decorrer da exposição ao chumbo $(\mathrm{Pb})$ metálico e aos seus compostos iónicos nos locais de trabalho, contém o VLE e o IBE do $\mathrm{Pb}$ [7]. O valor de concentração do chumbo no ar dos locais de trabalho não deve ultrapassar os 150 microgramas $/ \mathrm{m}^{3}$, referidos a 8 horas diárias e 40 horas semanais. O IBE é fixado em 70 microgramas por $100 \mathrm{ml}$ de sangue, em que o ALAU deve ser inferior a $20 \mathrm{mg} / \mathrm{g}$ de creatinina.

\section{CONCLUSÕES}

Os IBE são uma mais valia para prevenir a ocorrência de doenças profissionais dos trabalhadores expostos a substâncias químicas nocivas muitas vezes existentes nos locais de trabaIho. A relação existente entre os VLE e os IBE demonstra que os primeiros nunca devem ser ultrapassados nos postos de trabalho, de forma a minimizar os efeitos que causam nos trabalhadores expostos e o bem-estar da população em geral. A CT-42, que está a transpor e a atualizar os valores constantes do documento da ACGIH, compromete-se a atualizar bianualmente os valores produzidos nos Estados Unidos da América para o quadro normativo interno, a ser publicado como uma NP, pelo Instituto Português para a Qualidade (IPQ).

\section{REFERÊNCIAS}

[1] Limites de Exposición Profesional para Agentes Químicos em España, INSHT, 2011.

[2] J.P. Sousa, Doenças causadas por Agentes Biológicos, Proelium, 8 (2007) 191-212.

[3] J. Prista e A. Sousa Uva, A utilização de indicadores biológicos em saúde ocupacional, Revista Portuguesa de Saúde Pública, 6 (2006) 45-54.

[4] H. Rosa, Biomonitoramento, $12^{\circ}$ Congresso da ANAMT, maio 2004, Brasil.

[5] ACGIH, Professional Exposure Limits to Chemical Agentes at Workplace, E.U.A., 2009

[6] J.P. Sousa, M.L. Pereira e A. Rodrigues, Valores limite de exposição (VLE) a agentes químicos, Revista Proelium (2011).

[7] Decreto-Lei n. ${ }^{\circ} 247 / 89$, DR - I Série, № 191 , de 21 de agosto de 1989

\section{Atualdode CientiFica}

\section{Separação de Gases usando Nanoporos de Grafeno}

Cientistas da Nova Zelândia, EUA e Alemanha, desenvolveram uma forma de usar grafeno para separar isótopos de hélio. Pela formação de orifícios à nanoescala, os investigadores calcularam que seria possível alterar a permeabilidade do grafeno de modo a permitir a passagem de isótopos hélio-3 e simultaneamente não permitir a passagem dos isótopos hélio-4. Esta abordagem tem aplicações potenciais na produção de hélio-3 para investigação científica, como também para a separação de gases noutros contextos. O hélio-3 está presente na atmosfera numa razão de 1,4 partes de hélio-3 por um milhão de partes de hélio-4. É usado extensivamente em investigação de processos de fusão e em química de baixa temperatura, sendo a maioria do hélio-3 obtido por decaimento radioativo de trítio. No entanto, a procura por hélio-3 tem aumentado consideravelmente nos últimos anos e a captura de hélio-3 das fontes terrestres de hélio ajudaria a satisfazer esta necessidade. Usando cálculos teóricos e simulações, os investigadores descobriram que a remoção de anéis de uma folha de grafeno permitia reduzir a sua barreira energética, o que determina a sua permeabilidade. No entanto, esta abordagem não era suficientemente sensível para atingir o potencial necessário para permitir a passagem do hélio-3 sem passar hélio-4. A funcionalização dos nanoporos criados permitiu aos investigadores modificar a barreira energética de modo a que a separação seja possível, descoberta que poderá um dia permitir uma separação dos dois isótopos com um fluxo gasoso industrialmente aceitável.

(adaptado de http://www.rsc.org/chemistryworld/News/2012/May/graphene-nanopore-gas-separation-helium.asp)

Helder Gomes (bquimica@ipb.pt) www.spq.pt 


\section{All about Heterogeneous, Homogeneous, and BioCatalysis}

\section{Editorial Board Chairmen:}

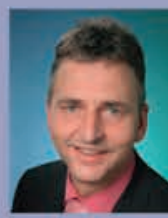

Prof. Uwe Bornscheuer Greifswald University, Germany

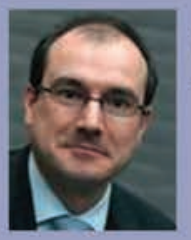

Prof. Bert Weckhuysen Utrecht University, The Netherlands

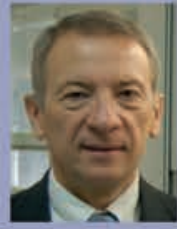

Prof. Luis A. Oro University of Zaragoza, Spain

\section{Focus}

- heterogeneous catalysis

- homogeneous catalysis

- biocatalysis

- protein engineering

- whole cell catalysis

- electrocatalysis

- photocatalysis

- organocatalysis

- metal catalysis

- asymmetric catalysis

- industrial catalysis

- nanocatalysis

- catalytic processes

- surface reactions

- in situ techniques

- spectroscopic methods

- theoretical methods

- catalyst preparation
Heterogeneous \& Homogeneous \& Bio-

\section{CHEMCATCHEM}

\section{CATALYSIS}

chemoenzymatic sis synthesis

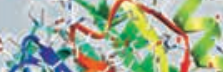

in

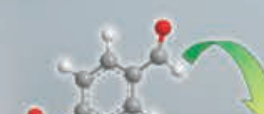

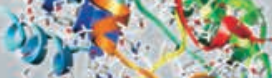
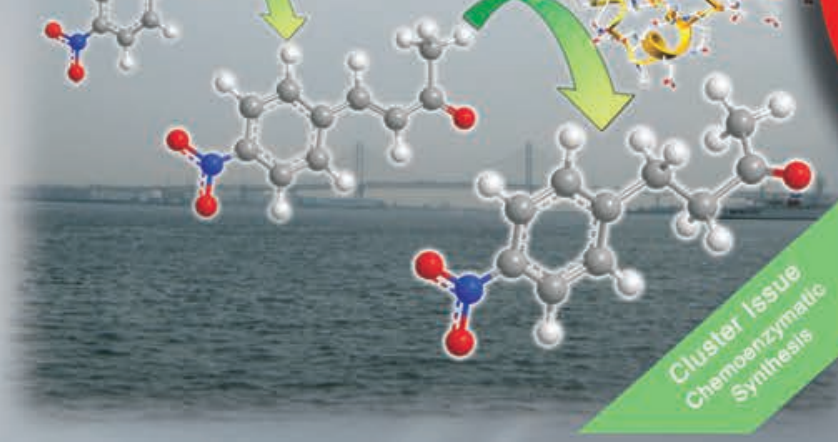
the future and subscribe now!

A journal of

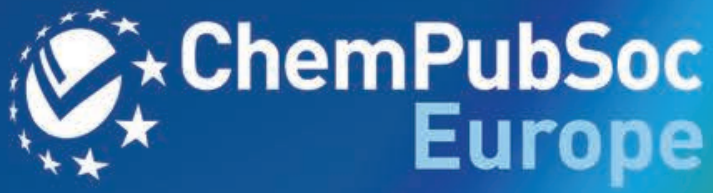

